\title{
Evaluation of Eye: Vision Sciences
}

\author{
Johanna Garzon P* \\ Department of Ophthalmology, University of La Salle, Colombia
}

*Corresponding author: Johanna Garzon P, Department of Ophthalmology, University of La Salle, Leader research group Primary Visual and Ocular Care, Colombia.

\section{Editorial}

Research is an important aspect of vision sciences, the ability to learn, achieve high levels of training that are fed back into the exercise, and contribute to excellence for patients, is the answer to improve professional performance. I believe that research is a fundamental part of the educational process, since professionals are always learning, discovering things, analyzing information, adapting their behavior according to the information received, looking for new things and improving what they have or adapting their knowledge to demands modern I want to extend the contribution of women of science, who have resorted to research for the benefit of visual health and the eyes of the community. The professionals that shine for their dedication, commitment and the contribution they have made to visual health; Participation in research projects, scientific and administrative directions of universities and educational institutions and incorporated, incorporates nuances of equality, dedication and commitment.

On the other hand, the world of ophthalmology and optometry has a great contribution of the industrial, technological advances and the commercialization of these; However, it is very important to maintain the freedom and purity of academic research and teaching, without incurring biases induced by the industry. Therefore, the invitation to all authors, authors and collaborators of our magazine, to publish research articles that seek to contribute to visual health and away from commercial prejudices.

In this issue of our journal, the reader will have the opportunity to read articles on interesting research related to new advances in external diseases, methods of correction and treatments, surgical techniques and postsurgical findings, physiological characteristics in vision and others. In addition, readers will find a review of the literature on different topics, which is important for the world of ophthalmology and optometry.

\section{Acknowledgement}

None.

\section{Conflicts of Interest}

No conflicts of interest. 